\title{
The Cultural Content in Teaching and Learning BIPA at Wako University of Japan
}

\author{
Gusdi Sastra $^{1}$, Dwi Susanto ${ }^{2}$ \\ ${ }^{1}$ Fakulty of Humanities of Andalas University, Padang \\ ${ }^{2}$ Fakulty of Literary Studies Sebelas Maret University, Solo \\ ${ }^{1}$ gusdi@hum.unand.ac.id
}

\begin{abstract}
This paper explains the Indonesian cultural content for BIPA teaching and learning materials in even semester at Wako University of Japan. There are 20 students, male and female, and 2 teachers. The Indonesian cultural content includes kinship, arts, culinary, tourism, and hobbies. These aspects are the local content in teaching Bahasa Indonesia for Wako University students since they are about to study in Indonesia for a short period. The results of this research show the students are interested in those five cultural aspects. They are mostly attracted to the culinary, and they are less interested in the aspects of kinship. Thus, the results of using the learning materials on Indonesian cultural content show the students' tendency or specific interests in learning BIPA. There are some factors explaining this percentage of interests as follow: purpose, method, and learning time. Those materials of cultural content and factors are observed through students' proficiency on reading, writing, listening, and speaking.
\end{abstract}

Keywords: Wako university, cultural contents, cultural aspects, teaching and learning BIPA,

\section{PENDAHULUAN}

Penulis bersama tim mendapat kesempatan untuk mengajar bahasa Indonesia selama 2 semester di salah satu universitas di wilayah Tokyo, Jepang, yaitu di Wako University yang dimulai pada semester genap tahun ajaran Jepang dan dibiayai oleh Dikti Indonesia. Wako University didirikan oleh Dr. Satoru Umene tahun 1966. Sampai sekarang, universitas ini terdiri dari 3 fakultas, yaitu (1) Fakultas ilmu kemanusian dengan beberapa departemen: psikologi dan pendidikan, ilmu sosiologi, dan lingkungan kesejateraan manusia, (2) Fakultas studi representasi dengan dua departemen: transkultural dan seni, (3) Fakultas ekonomi dan manajemen bisnis dengan departemen: ekonomi, bisnis dan media. Salain itu, universitas ini juga mempunyai program pascasarjana dengan program studi ilmu sosial dan budaya.

Sebagai sebuah universitas yang tidak begitu besar di Jepang, tetapi universitas ini mempunyai komitmen yang tinggi dalam pengembangan sumber daya manusia Jepang terutama bidang ilmu sosial dan budaya. Dengan jumlah profesor dan asisten profesor yang memadai lebih dari 100 orang, kampus ini sudah menjadi tempat tujuan perkuliahan bagi mahasiswa Jepang baik di sekitar wilayah Tokyo maupun dari luar wilayah Tokyo. Berlokasi di daerah perbukitan Tsurukawa di luar perbatasan area Tokyo, kampus ini nyaman dan tenang untuk 
belajar bagi mahasiswa Jepang. Di kampus ini juga mengajar beberapa orang dosen yang berasal dari berbagai negara lain, seperti India, Cina, Malaysia, Thailand, Vietnam, Indonesia, Pilipina, juga dari Eropa dan Amerika dari berbagai bidang keilmuan selain bangsa Jepang sendiri.

Keterkaitan langsung dengan ilmu sosial budaya dari berbagai bidang keilmuan di Wako University, membuat mahasiswanya harus mengenal bahasa dan kebudayaan negara-negara lain, terutama dengan bebarapa negara di Asia. Salah satunya adalah dengan bahasa dan budaya Indonesia. Sebagian besar mahasiswa dari berbagai departemen yang ada di universitas ini, berminat mengambil mata kuliah pilihan bahasa dan budaya Indonesia. Artinya, kajian tentang Indonesia baik dari aspek bahasa maupun budaya bukanlah sebuah departemen di universitas ini, melainkan mata kuliah kluster yang dapat saja diambil oleh mahasiswa dari berbagai departemen atau program studi. Selain untuk perbandingan Jepang dengan beberapa negera di asia, juga untuk tujuan kunjungan wisata dan studi banding. Hampir setiap tahun pada liburan musim panas rombongan mahasiswa dari kampus ini berkunjung ke berbagai negara termasuk Indonesia, kepada mereka sudah dikenalkan bahasa dan keanekaragaman budaya yang ada di Indonesia.

Makalah ini akan membahas tentang muatan budaya dalam pembelajaran bahasa Indonesia untuk mahasiswa asing, khususnya mahasiswa Jepang yang kuliah di Wako University. Perkuliahan diberikan pada semester genap yaitu dari bulan Oktober sampai Februari dan semester ganjil bulan April sampai Agustus dalam dua mata pelajaran yang ditugaskan kepada penulis dan tim, yaitu berbicara dan tatabahasa. Kedua mata kuliah ini diwujudkan melalui empat keterampilan berbahasa yaitu membaca, menulis, menyimak, dan berbicara.

\section{METODE PENELITIAN}

Penelitian ini merupakan studi kualitatif dengan menerapkan strategi yang sesuai dalam proses pembelajaran bahasa Indonesia terhadap pembelajar, yaitu mahasiswa asing pembelajar BIPA di Wakto University Jepang dengan jumlah subjek sebanyak 20 orang. Strategi yang dimaksud adalah menyusun muatan budaya dalam mempersiapkan materi pembelajaran yang disusun dalam 4 ranah budaya, yaitu kekerabatan, kesenian, kuliner, dan rekreasi/hobby. Walaupun masih banyak lagi ranah budaya lain yang harus dibahas, namun 4 ranah ini dianggap cukup mewakili karena keterbatasan waktu dan tujuan pembelajaran BIPA yang diajarkan di Wako university ini.

Pengumpulan data dilakukan selama satu semester setiap terjadi proses belajar mengajar. Teknik yang digunakan adalah uji model atau penerapan berbagai ranah budaya melalui pembelajaran secara acak, dengan melihat faktor-faktor penentu pembelajaran. Hasil uji strategi pembelajaran pada minggu pertama, dievaluasi pada minggu-minggu berikutnya, lalu dilengkapi dengan muatan budaya melalui strategi pembelajaran secara eksternal dengan memperhatikan faktor-faktor luar seperti tujuan, cara, dan waktu pembelajaran, kemudian memasukkan ke dalam materi keterampilan berbahasa membaca, menulis, menyimak, dan berbicara.

\section{HASIL DAN PEMBAHASAN}

\subsection{Pembelajaran BIPA di Wako University}

Pembelajaran BIPA (Bahasa Indonesia untuk Penutur Asing) di Wako University tidak jauh berbeda dengan proses perkuliahan pada umumnya, ada ruangan kelas dan meja yang disusun letter U. Ruang belajar tidak begitu besar dan paling banyak dapat ditempati oleh lebih kurang 15 mahasiswa. Di kelas sudah tersedia LCD projector, OHP, Telivisi, dan audio system. Jadi pengajar tinggal tekan tombol dan menghubungkan kabel dengan note book. Selain itu tetap 
tersedia white board dan penghapus. Jadi tidak jauh berbeda dengan ruang belajar BIPA pada umumnya di Indonesia. Perbedaannya, kalau di Indonesia mahasiswa bisa dibawa langsung ke lapangan, atau kuliah di alam terbuka, tetapi mahasiswa di sini praktek lapangan hanya dapat melihat melalui cd atau rekaman video saja tentang gambaran tema pelajaran. Apabila mahasiswa dibawa kuliah di alam terbuka, sulit juga karena alam bebas terasa dingin (pada semester genap - apalagi pada musim dingin dari bulan oktober sampai februari) dan angin cukup kencang. Oleh sebab itu, mahasiswa menerima materi pelajaran hanya di dalam ruangan saja. Jika mahasiswanya rajin, maka dapat menggunakan perpustakaan untuk memperdalam materi. Pengalaman di sini mahasiswa jarang sekali diberi tugas oleh dosen. Mahasiswa lebih banyak memperdalam materi melalui buku-buku yang tersedia di perpustakaan.

Mahasiswa yang mengambil kuliah BIPA ini tergabung dari beberapa departemen lain dari 3 fakultas yang ada. Mereka mengambil kuliah bahasa Indonesia sebagai mata kuliah kluster dan biasanya untuk tujuan penelitian dan kunjungan ke negara tujuan (Indonesia). Kalau dilihat cara belajar mereka, cukup santai namun apabila diperhatikan mereka banyak di perpustakaan belajar sendiri, kecuali jam makan siang di kafetaria atau kuliah di ruangan selama 1 jam 30 menit.

Cara mahasiswa belajar dalam ruangan bermacam-macam, ada yang serius dan ada pula yang kelihatan santai. Jadi cara belajar di luar negeri berbeda dengan cara dan aturan belajar mengajar di Indonesia. Walaupun mahasiswa tidak bisa menjawab pertanyaan dari latihan yang diberikan, tidak akan beresiko terhadap nilai mereka, karena sistem pembelajaran mereka tidak mengharapkan nilai akhir. Tidak ada ketentuan yang mengharuskan mereka harus lulus dalam mata pelajaran ini. Dengan demikian menjadi pengajar BIPA di luar negeri harus mengerti dan mempunyai strategi dan model pembelajaran yang sesuai dengan situasi dan kondisi [1], apalagi mahasiswa mempunyai latar belakang bidang ilmu berbeda dan pengetahuan kebahasaan dan minat yang berbeda.

Setiap mata pelajaran (membaca, menulis, menyimak, berbicara) berbeda jumlah mahasiswa yang mengambil, berbeda pula umur, pengalaman dan pengetahuannya tentang Indonesia. Oleh karena itu sangat diperlukan kepintaran pengajar dalam menyikapi kondisi yang demikian, misalnya dengan lebih memperhatikan mahasiswa yang kurang, dan menyuruh mahasiswa yang pintar untuk menjelaskan lebih banyak lagi contoh, atau memisahkan mereka menjadi kelompok kecil sambil mendiskusikan materi dan contoh kalimat. Selain itu, penayangan materi melalui infocus dapat menimbulkan ketidakbosanan mereka, misalnya video tentang Indonesia. Dengan demikian pembelajaran dapat menyaksikan langsung gambaran tentang Indonesia melalui berbagai aktivitas yang ada dalam video. Penggunaan media visual sangat bermanfaat untuk pembelajar di sini karena dapat melihat langsung peristiwa materi yang sedang dibicarakan. Bahkan foto-foto atau video tentang kegiatan budaya dapat dijadikan sebagai alat dalam pembelajaran pengenalan Indonesia. Pembelajar tidak cukup hanya belajar tatabahasa Indonesia, tetapi dapat menggunakannya dalam setiap peristiwa budaya yang nampak melalui media visual. Apabila mereka sudah pernah ke Indonesia, maka kelihatan dari wajahnya untuk ingin datang kembali ke Indonesia, sedangkan bagi yang belum pernah ingin sekali ke Indonesia apalagi untuk tujuan studi banding liburan musim panas.

\subsection{Muatan Budaya dalam Pembelajaran BIPA di Wako University}

Menyikapi proses pembelajaran BIPA di Wako university, maka penulis bersama tim menyusun suatu materi pembelajaran berangkat dari muatan ranah budaya Indonesia [2]. Pendekatan empiris menurut Bloomfield dan rasional menurut Chomsky, dipadukan melalui muatan budaya dalam proses pembelajaran [3]. Metode ini sangat efektif karena dari penilaian yang diberikan, semua pembelajar terampil dalam menjawab pertanyaan, baik tertulis maupun 
lisan. Berbagai keterbatasan dapat diminimalisir melalui materi ajar yang telah disusun sesuai ranah-ranah budaya yang dipilih dalam pembelajaran BIPA di Wako university ini.

Penyususunan materi disiapkan atas 4 ranah budaya [4] yang sudah dipilih. Adapun sub-sub topik yang dibahas dalam setiap ranah antara lain: (1) Ranah kekerabatan; nama diri, panggilan, sapaan, dan gelar. (2) Ranah kesenian; seni tari, seni musik, dan seni suara. (3) Ranah kuliner; sarapan, makanan, minuman, dan kuliner tradisional. (4) Ranah Rekreasi/kegemaran hobby; daerah wisata dan kegemaran.

Pemahaman pembelajar terhadap keempat ranah budaya tersebut dipengruhi oleh beberapa faktor internal dan eksternal [5], yaitu tujuan pembelajar mengikuti pembelajaran, cara pembelajar dalam mempelajari materi, dan waktu yang digunakan pembelajar dalam proses pembelajaran keseluruhan aspek budaya yang sudah dijelaskan, baik melalui materi buku berupa teks dan gambar, maupun dari penayangan video dan foto. Pemahaman pembelajar terhadap budaya Indonesia, dilihat berdasarkan keterampilan reseptif dan produkstif pengetahuan budayanya. Selain itu, melalui ketrampilan membaca, menulis, menyimak, dan berbicara pembelajar, dapat dilihat penguasaan tatabahasanya [6]. Perbandingan penguasaan materi antara ranah-ranah budaya, faktor dan keterampilan pembelajar dapat dilihat dari grafik hasil test terhadap 10 orang pembelajar BIPA di Wako university ini:

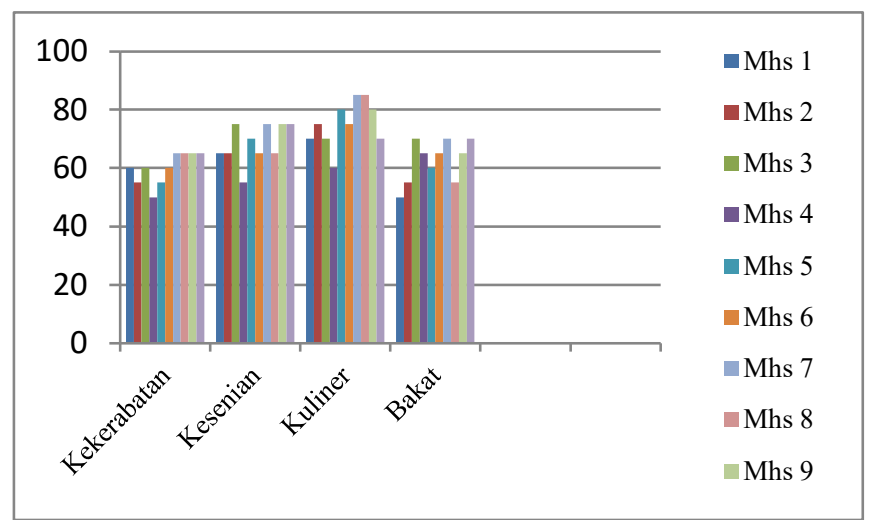

Berdasarkan hasil penghitungan nilai akhir pembelajar dalam menguasai berbagai ranah budaya, maka terlihat kecendrungan pembelajar lebih cepat menguasai materi kuliner terkait dengan makanan, minuman, dan makanan tradisional. Persentase yang cukup bagus ini pertanda bahwa pembelajar menyukai topik ini karena salah satu cara yang dilakukan adalah praktikal kuliner di kampus serta penayangan foto-foto kuliner Indonesia. Uji coba langsung memasak masakan tradisional Indonesia seperti nasi goreng dan rendang, menambah minat dan kesukaan mereka disela kegiatan kebudayaan yang ada di universitas ini. Begitu juga dengan ranah budaya kesenian [7], adanya praktek langsung mengajarkan tarian tradisional serta nyanyian anak-anak Indonesia, mempermudah mereka dalam mengenal budaya Indonesia dan mempraktikan bahasa Indonesia sesuai materi yang mereka dapatkan melalui setiap ranah budaya yang sudah diperkenalkan.

Berbagai ranah budaya yang dikuasai oleh pembelajar tersebut, dipengaruhi oleh beberapa faktor yang mendukung [8], yaitu tujuan, cara, dan waktu yang digunakan oleh pembelajar dalam memahami materi di setiap ranah budaya pada berbagai keterampilan membaca, menulis, menyimak, dan berbicara. 


\section{SIMPULAN}

Pembelajaran BIPA di Wako University Jepang secara umum bahwa bahasa Indonesia ramai diminati oleh mahasiswa asing untuk berbagai tujuan. Pengetahuan tentang Indonesia semakin banyak dilakukan di berbagai negara, khususnya Jepang yang sudah lama mempunyai hubungan kerjasama luar negeri dengan berbagai negara termasuk Indonesia sehingga bahasa Indonesia diajarkan di beberapa universitas di Jepang. Banyak para mahasiswa di Jepang sudah mengetahui jauh tentang Indonesia dari barat sampai ke timur. Bahkan di Wako University sendiri diajarkan berbagai hal tentang asia termasuk Indonesia oleh seorang profesor kebangsaan Indonesia yang sudah menjadi profesor tetap di Wako unversity ini.

Dengan latar belakang keilmuan pembelajar yang berbeda-beda, yakni dari berbagai departemen yang ada di Wako University, maka diperlukan sebuah strategi pengajaran BIPA yang efektif untuk mengajar BIPA yang bukan di Indonesia, salah satunya adalah dengan mengintegrasikan budaya dalam materi pembelajaran [9]. Secara umum proses pembelajaran bahasa Indonesia di Wako University lebih memperhatikan aspek tujuan pembelajar belajar bahasa Indonesia dan situasi pembelajar ketika mempelajari bahasa Indonesia [10]. Faktorfaktor yang memudahkan pembelajar menguasai bahasa Indonesia di universitas ini adalah adanya tujuan belajar yang jelas, cara, dan waktu belajar, sedangkan ranah-ranah budaya yang diperkenalkan kepada pembelajar cukup efektif yaitu ranah kekerabatan, kesenian, kuliner, rekreasi/bakat melalui teks dan kosa kata budaya Indonesia di setiap ranah. Penguasaan ranah budaya ini dapat meningkatkan ketrampilan berbahasa pembelajar melalui membaca, menulis, menyimak, dan berbicara [11]. Persentase terbaik yang dikuasai pembelajar adalah pada ranah kuliner. Salah satu faktor tingginya nilai mahasiswa pada ranah ini mungkin disebabkan oleh karena adanya cara yang tepat melalui pratikal memasak yang dilakukan bersama-sama pembelajar [12].

\section{UCAPAN TERIMA KASIH}

Terima kasih kepada bagian kerjasama luar negeri Dikti yang telah membiayai tugas mengajar BIPA ke Jepang, terima kasih juga kepada rector universitas andalas dan rektor universitas sebelas maret atas izin dan dukungannya. Teristimewa terima kasih disampaikan kepada rektor wako university, atase pendidikan KBRI Tokyo, prof. bambang rudianto beserta professor di program studi ilmu sosial dan budaya wako university beserta seluruh mahasiswa yang mengikuti pembelajaran BIPA di wako university angkatan 2011

\section{REFERENCES}

[1] Awang Sariyan. "Bahasa dan Pendidikan Bahasa" Mana Sikana et.al (Ed). Teori Pemikiran dan Tamadun Melayu. Johor: Dewan Bahasa dan Pustaka. 2013.

[2] Be, Anny. "Masalah-masalah dalam Komunikasi Antar Budaya dan Analisis Kontrastif Indonesia-Inggris. Jurnal Pendidikan Bahasa. 2011.

[3] Brumfit, C. Communicative Methodology in Language Teaching. Cambridge: University of Cambridge. 2000.

[4] D. Mardapi and B. Kartowagiran, "Pengembangan Instrumen Pengukur Hasil Belajar Nirbias dan Terskala Baku," J. Penelit. dan Eval. Pendidik., 2019

[5] Fanany, R. "Getting Students to Think and Speak in Another Culture". National LOTE Conference. Mebourne. 2000.

[6] Fanany, R. Modifikasi Kognitif dan Usur Budaya dalam Pengajaran Bahasa. Universiti Putra Malaysia. 2004. 
[7] Kramsch, C. Context and Culture in Language Teaching. Oxford: Oxford University Press. 1993.

[8] La ntolf, JP. "The Struggle for a Place in the Sun: Rationalizing Foreign Languag Study in The Twentieth Century". Modern Language Journal, 85, 5-25. 2011.

[9] Rani, A. “Aspek Sosiolinguistik dalam Pengajaran Bahasa Indonesia untuk Orang Asing. Konferensi Nasional Pengajaran BIPA. 2014.

[10] Sastra, G. "BIPA di Hamburg University". Jurnal Puitika. 2012.

[11] Wolf, U et al. Beginning Indonesia Through Self Instruction 1,2,3. Jakarta: Gramedia Book Publishing Division. 2015.

[12] K. Saddhono, "Integrating culture in Indonesian language learning for foreign speakers at Indonesian universities," J. Lang. Lit., vol. 6, no. 2, 2015. 